Perio-feminismo desde adentro. Desigualdades de género en los medios

Florencia Rovetto, Lucía Figueroa

Con X (N. ${ }^{\circ}$ 4), e022, 2018

ISSN 2469-0333 | https://doi.org/10.24215/24690333e022

http://perio.unlp.edu.ar/ojs/index.php/conequis

FPyCS | Universidad Nacional de La Plata

La Plata | Buenos Aires | Argentina

\title{
Perio-feminismo desde adentro Desigualdades de género en los medios
}

\author{
Femi-journalism from inside. Gender inequalities in the media
}

\author{
Florencia Rovetto \\ florencia.rovetto@cifegunr.com \\ Lucía Figueroa \\ lulafigueroa87@cifegunr.com \\ https://orcid.org/0000-0001-5900-9630 \\ Centro de Investigaciones Feministas y Estudios de Género (CIFEG) \\ Facultad de Ciencia Política y RRII \\ Universidad Nacional de Rosario | Argentina
}

\section{Resumen}

En un contexto marcado por la gran presencia en la agenda pública internacional del movimiento de mujeres, las autoras reflexionan sobre el trabajo de mujeres periodistas a partir de analizar sus percepciones sobre el clima de época. Se realizaron una serie de entrevistas que favorecieron la emergencia de narrativas desde la visión de las propias trabajadoras jóvenes periodistas. Las dimensiones abordadas fueron la inequidad en el reparto de las tareas y funciones, sus participaciones en colectivas feministas, formas de activismos en red, producción y circulación de contenidos con perspectiva de género, agenciamientos, feminización del ejercicio profesional.

Palabras clave | periodismo, feminismo, medios de comunicación

\section{Abstract}

In a context signed by a huge presence of women's movement on the international public agenda, the authoress ponder women-journalists' work, by analyzing their views on about the spirit of the times. A series of interviews were conducted to approach to the workers perspective about this issue. The dimensions addressed were the inequality in tasks distribution at job, their participation in feminist collectives, forms of net activism, production and circulation of content with gender perspective, agency, feminization of professional practice and activism practices.

Keywords | journalism, feminism, mass media 


\title{
Perio-feminismo desde adentro
}

\author{
Desigualdades de género en los medios
}

\author{
Por Florencia Rovetto y Lucía Figueroa
}

\section{Introducción}

Los debates que tematizan el cruce entre género y medios de comunicación tienen décadas de existencia, pero no suelen ocupar el prime time de la televisión abierta ni las páginas centrales en los periódicos o en los informativos de las emisoras radiales. Sin embargo, en la Argentina, desde principios de 2018, en un proceso de escalada constante y sin precedentes, los medios de comunicación masivos comenzaron a abordar temas vinculados a las históricas reivindicaciones de los movimientos de mujeres y feministas (Spataro, 2018), mientras los hashtag \#soyfeminista y \#abortolegal se instalaron vertiginosamente, replicándose y creando tendencia en todas las redes sociales. ${ }^{1}$

La irrupción de temáticas vinculadas a las reivindicaciones y a luchas feministas en la agenda mediática argentina produjo un gran revuelo en la opinión pública antes de la multitudinaria movilización del \#8M y continuó con la llegada del debate por la despenalización del aborto al Congreso de la Nación, en abril de 2018. Este fenómeno, que podríamos nombrar como popularización del feminismo, se visibiliza claramente a partir del primer NiUnaMenos (NUM), ${ }^{2}$ en 2015 y tiene un alcance que aún no se dimensiona en su totalidad, aunque las impactantes imágenes del pañuelazo de comienzos de junio funcionen como un indicador de masividad. 
El colectivo NiUnaMenos, como organización de referencia a nivel nacional, se constituyó al calor de la organización de la primera convocatoria a movilizarse con ese slogan, ${ }^{3}$ el 3 de junio de 2015, dando lugar a la conformación de colectivas que con ese mismo nombre y con improntas singulares seguirán instituyéndose en distintas ciudades del país (López, 2015, en línea).

Así, de forma constante, y, por momentos, convulsiva, temáticas otrora marginales o invisibilizadas en y de los propios medios de comunicación se incluyeron en la agenda de la mano de las comunicadoras y las periodistas organizadas de cara a la segunda Huelga (Paro) Internacional de Mujeres (8M). ${ }^{4}$ En efecto, el acoso y las violencias sexistas en las industrias culturales, ${ }^{5}$ el «techo de cristal» en los ámbitos de trabajo periodísticos, la brecha salarial, las licencias por aborto, parentales o por violencia de género, fueron algunos de los temas que comenzaron a tallar con fuerza en distintos medios y, en muchos casos, desde la voz de sus protagonistas.

\section{De la reacción a la acción organizada}

En las redes se pueden ubicar el origen y la visibilidad viral de la convocatoria a la que sería la primera y más masiva movilización nacional contra las violencias sexistas, en 2015. Con una frase que ya estaba instalada y que recorría como un susurro las plataformas virtuales de comunicación, en pocas horas se alcanzó un momento de condensación, provocando la circulación de una gran cantidad de imágenes, compuestas, principalmente, por ilustraciones que incluían el hashtag \#NiUnaMenos y la referencia a marchar el 3 de junio, en más de sesenta ciudades de todo el país.

Al respecto, María Pía López (2005), integrante de NUM Buenos Aires, señala:

[...] si esto cuajó es porque había algo que lo preexistía, una conjunción entre ánimo social y trabajo minucioso de los grupos activistas que venían, con empecinamiento necesario aunque tantas veces desoído, tratando de llamar la atención sobre la cuestión (en línea). 
Así, la inmediata circulación del unívoco mensaje aglutinó, detrás de una sola consigna -iNI UNA MENOS!-, a una polifónica multitud (Toret, 2013) conformada por heterogéneos agentes que se sumaban a repudiar las violencias sexistas a través de incontables páginas y perfiles web (Rovetto, 2015). El tema ya estaba en las calles, en los medios de comunicación y en las redes, solo faltaba «una chispa» para que ardiera. ¿Quién podría quedar al margen de manifestarse públicamente en contra de los asesinatos de mujeres?

Así, según López (2015), con una masividad inaudita, NUM, en pocas horas,

[...] se convirtió en un territorio profuso, en el que comenzaron a coexistir retóricas de distinto tipo, inteligencias diversas, apuestas políticas no sólo heterogéneas sino contradictorias, tenacidades militantes y organizativas, novedades tecnológicas, compromisos feministas y pericia en medios de comunicación (en línea).

Lo novedoso de esta reacción fue haber alcanzado mejores condiciones de emergencia y de visibilidad, y es ahí donde podemos reconocer el gesto organizativo del movimiento feminista en el presente. Al acumulado de experiencia en sus luchas históricas se suma la capacidad de «habilitar los tránsitos, los desplazamientos, la valoración de los márgenes, de lo intersticial» (Arfuch, 2008, p. 208). Es allí, donde, según Nelly Richard (2009), radica el doble sentido de la crítica cultural y el activismo feminista. Es crítica de la cultura, en tanto escruta y subvierte los regímenes de producción y de representación del poder que circula y que se intercambia como palabra, gesto e imagen. Al mismo tiempo que es acción política desde la cultura, al incorporar trabajo expresivo y narrativas como fuerzas de cambio. O, al decir de la escritora y periodista María Moreno (Palomo, 2018), «moverse estratégicamente en lo establecido para transformarlo e incluso invertir su sentido» (en línea).

De esta manera, NUM también condensa las reivindicaciones de las mujeres periodistas que llevan más de una década organizándose, ${ }^{6}$ ampliando el horizonte de sentidos vinculados a la violencia de género y combinando sus demandas con el conjunto social más amplio. La capacidad de visibilizar la violencia de género en todos los ámbitos, así como las múltiples formas en que la misma se expresa y sus 
formas de tradición naturalizada en los medios de comunicación, ha sido el eje vertebrador de las entrevistas realizadas a las mujeres periodistas de la ciudad de Rosario.

Su activa participación se entrama en consignas y en modalidades de organización en un contexto atravesado por el avance del movimiento de mujeres y por políticas de ajuste, de precarización y de multifunción en las empresas periodísticas. Si bien el colectivo NUM Rosario tiene una fuerte impronta intergeneracional, en esta ocasión hemos optado por sistematizar los testimonios de las periodistas y las comunicadoras más jóvenes. Estas periodistas, que han iniciado recientemente sus carreras profesionales, se encuentran profundamente afectadas por las condiciones de explotación. Sus testimonios dan cuenta de la potencia y de la determinación de sus acciones, pero también de los innumerables obstáculos que tienen que atravesar para disputar la palabra y para trasformar sus condiciones de producción y de circulación.

\section{Feminismos en la agenda}

En los últimos tiempos, las demandas y las reivindicaciones feministas se incorporan en los medios de comunicación de múltiples maneras. Por ejemplo, a un mes de la segunda Huelga Internacional de Mujeres, en un programa dedicado al espectáculo televisivo, que cuenta con la mayor audiencia de la tarde en la Argentina, se convocó a reconocidas activistas y comunicadoras feministas. Este tipo de programas, también llamados programas de chimentos o de rumores, otrora desprestigiado por los estudios en comunicación y cultura locales, incorpora temáticas vinculadas a géneros y a sexualidades dando voz a quienes producen sentidos en clave de derechos igualitarios (Spataro, 2018).

¿Cómo llegan las principales demandas del movimiento feminista a elevar los puntos del raiting televisivo o ser trending topic en twitter? ¿Qué rol cumplen las redes sociales en la instalación de esta agenda? ¿Qué implicancias tiene para el ejercicio periodístico el feminismo mediatizado? ¿Cómo se imbrican las luchas del movimiento político más dinámico en la actualidad con la agenda informativa? 
Estos interrogantes nos acercan a observar las prácticas de las jóvenes periodistas, integrantes del colectivo NUM, para reflexionar en torno al desarrollo de su trabajo y de sus experiencias militantes, en un contexto que muestra las caras más violentas del patriarcado y las políticas neoliberales, a la par del avance del movimiento feminista a nivel internacional.

Sostenemos que estas trabajadoras de medios, productoras de contenidos informativos o perio-feministas realizan una tarea militante indispensable, subvirtiendo los modos tradicionales de "hacer noticias», acompañando luchas y reivindicaciones, y poniendo en agenda temáticas cruciales vinculadas a los derechos de las mujeres, y lo realizan, cada vez, de forma más innovadora y con mayor capacidad de contagio.

El plafond que en la actualidad tienen temas invisibilizados y marginales en los medios de comunicación va de la mano de lo que se ha dado en llamar «cuarta ola del feminismo», con un internacionalismo más fuerte y visible, gracias a las redes sociales y los espacios infocomunicacionales. Como señala Marta Dillon, periodista e integrante de NUM, «la "masividad” del movimiento llega desde el Sur, desde los países más empobrecidos [...], habla muchas lenguas, tiene distintos colores y se nutre de experiencias diversas» (Díaz, 2017, en línea). Se fortalece contra la oleada neoliberal, los discursos antiderechos y cuestiona los feminismos corporativos e integrados al status quo que no buscan la transformación radical de las estructuras de dominación y de desigualdad.

Tal como afirma Nancy Fraser (2017), ${ }^{7}$ el presente pugna por un feminismo para el 99\% gracias al activismo radical con una orientación más clara y con plataformas de acción política que empiezan a atraer apoyos más amplios: «Hay mucha gente que se está radicalizando y politizando por primera vez», sostiene Fraser (2017, en línea), interpelando el desvío neoliberal y corporativo que los movimientos sociales «onegeistas» habían tomado en las últimas décadas.

Así, pues, las organizaciones y colectivas feministas, haciendo uso de redes sociales (twitter, face, instagram, etc.) con mayor capacidad de interacción y de viralización, abren paso a nuevas posibilidades de enunciación y a estrategias globales de acción política inéditas hasta el presente. Antes de cada movilización nacional o internacional circulan y se multiplican masivamente consignas que reflejan prácticas de acción del movimiento más activo y dinámico en el país y en el mundo: \#NiUnaMenos, \#VivasNosQueremos, \#NosotrasParamos, \#AbortoLegalYa. 
Muchas jóvenes comunicadoras y feministas activistas iniciaron un camino novedoso con algunas certezas y, sobre todo, con muchas expectativas respecto de un futuro prometedor para habitar y para apropiarse del ciberespacio como terreno propicio para subvertir los códigos culturales androcéntricos y para instituir las propias visiones de mundo (Laudano, 2016).

Allí, la indispensable articulación entre feminismos y producción periodística de discursos contragehemónicos en torno a elementos socialmente significantes y cruciales en nuestras realidades contemporáneas —como las violencias sexistas, el aborto, las desigualdades producidas por la división sexual del trabajo en todos los ámbitos o la heteronormatividad obligatoria- emerge en discursividades y en acontecimientos que pueden ser leídos como «huellas» de las transformaciones producidas en las prácticas comunicativas (Verón, 1987).

El recorrido del colectivo NUM, tomado como caso de análisis para reflexionar sobre las prácticas perio-feministas, pone de relieve las posibilidades que brinda el contexto virtual para visualizar reivindicaciones y luchas, instalar agenda, desplazar sentidos hegemónicos, diseñar estrategias y construir nuevos pactos (Zafra, 2014) contra ese orden social desigual y opresivo que llamamos patriarcado.

Así, ubicamos la emergencia del perio-feminismo como parte fundamental de este movimiento social en auge, una verdadera práctica contrainsurgente que instituye formas cada vez más creativas, sutiles y certeras de disputar y de subvertir el orden hegemónico. Con la potencia de la resemantización de sus luchas, que pugnan por la construcción de un nuevo orden civilizatorio, sobre la base de nuevos pactos entre mujeres y con otros sectores sociales oprimidos (Femenías, 2002).

$\mathrm{Al}$ respecto de este vínculo entre feminismo y medios, desde un análisis que incluye los estudios culturales y los de género, María Belén Rosales (2016) reflexiona e interroga sobre el clima de época atravesado por elementos propios del ideario feminista: 
Los medios y la cultura popular han incorporado la perspectiva feminista produciendo nuevas significaciones de género que serían impensables sin el impacto del feminismo. En ejemplos contemporáneos, esto se observa en la irrupción de nuevos modelos de heroínas en los medios, de retóricas y de narrativas en torno a vínculos sexo-afectivos no heteronormativos, etcétera. Ahora bien, a esta visión optimista se siguen otros debates: ¿son estos logros una concesión de la industria? ¿Es la forma en la que el discurso hegemónico neutraliza los discursos oposicionales incorporándolos? (p. 24).

\section{Activismo perio-feminista}

Es innegable que el contexto social y político habilita debates y discusiones que ponen en la mira las desigualdades de género en todos los ámbitos. Y los medios de comunicación, en tanto espacios reproductores de dichas desigualdades — hacia afuera y hacia adentro—, no quedan al margen de esta interpelación. Por el contrario, en distintas partes del mundo las mujeres que trabajan en espacios de producción mediática se organizan local y regionalmente, visibilizando sus reivindicaciones en manifiestos públicos y en contenidos informativos que dan cuenta de sus demandas específicas.

Por ejemplo, en España, a principios de marzo de 2018, y bajo el lema «Las periodistas paramos», se inició una convocatoria que en pocos días logró el apoyo de más de 8 mil mujeres profesionales de los medios de comunicación, y que promovió un manifiesto en el que se denuncian todas las formas de desigualdades que afectan cotidianamente a las mujeres y a otras personas feminizadas en el sector. También animaron a colectivos de periodistas de otros países a realizar su propio manifiesto ${ }^{8}$ conscientes de la "relevancia social» del trabajo que desempeñan y para mostrar su preocupación «por la visión parcial de la realidad que tantas veces ofrecen los medios y en la que falta la presencia y aportaciones de las mujeres. El feminismo también es necesario para mejorar el periodismo» (Las periodistas paramos, s/f, en línea). 
En esta línea de acción, las periodistas de la ciudad de Rosario (Santa Fe, Argentina), donde centramos este estudio, realizaron la primera asamblea de mujeres del sector en el marco del Sindicato de Prensa Rosario, de cara a organizar la jornada del \#8M a nivel local. Esta jornada contó con la participación de periodistas y de comunicadoras que realizan su labor en diversos medios privados, comerciales, cooperativos, autogestionados, públicos, sin fines de lucro y de prensa institucional en la ciudad.

En esa ocasión, abordaron aspectos vinculados a la modalidad de la huelga y a la necesidad de incorporar a la estructura sindical un área que trabaje, específicamente, las problemáticas de género y de diversidad sexual. Al mismo tiempo, acordaron reclamar capacitación en los medios de comunicación para el ejercicio de un periodismo con enfoque de género, para visibilizar las problemáticas de las trabajadoras de prensa precarizadas y flexibilizadas, y para pronunciarse a favor de la despenalización del aborto, en vísperas de su tratamiento en el Parlamento Nacional.

Entre las periodistas reunidas en asamblea se destaca la participación de las integrantes del colectivo NUM Rosario, en cuyas narrativas se basa el análisis aquí presentado.

\section{Las experiencias perio-feministas en la actualidad: NUM Rosario}

En la ciudad de Rosario, el colectivo NUM es intergeneracional y está integrado por periodistas, artistas, investigadoras, docentes y activistas. Sus reivindicaciones están estrechamente articuladas con las del movimiento de mujeres y feminista a nivel local.

En la actualidad, las que trabajan en los medios de comunicación se encuentran afectadas directamente por los despidos, el no pago de salarios o de aumentos paritarios, la especulación empresarial, y la flexibilización y la precarización laboral que impactan duramente sobre el sector y que las afecta doblemente por ser mujeres. 
Un primer acercamiento al perio-feminismo nos condujo a encontrarnos con mujeres jóvenes periodistas con las que realizamos seis entrevistas individuales que si bien se estructuraron en base a ejes y a preguntas de investigación derivadas de un proyecto de mayor calado, ${ }^{9}$ se convirtieron en conversaciones reflexivas co-construidas al calor de la cuarta ola feminista.

En este artículo, nos centramos en el análisis de sus percepciones en torno a la articulación entre sus prácticas laborales y sus experiencias militantes, y recorremos sus valoraciones sobre la reciente irrupción del feminismo en la agenda mediática, el rol de las redes sociales y las nuevas tecnologías en la actualidad, y sus implicancias en el ejercicio periodístico.

El trabajo se presenta como un primer acercamiento a las prácticas periofeministas, a partir de entrevistas que recogen la perspectiva de seis mujeres jóvenes, integrantes del colectivo NUM Rosario, quienes se definen por su identidad laboral como periodistas, se autoperciben como feministas y hacen de sus prácticas infocomunicacionales un ejercicio profesional y militante al mismo tiempo. Las preguntas incluidas en la entrevista abordaron de manera integral estos dos grandes campos de intervención, el del periodismo y el feminismo, para reflexionar sobre sus prácticas cotidianas y para profundizar en las articulaciones que a lo largo de sus carreras fueron hallando en este vínculo.

Las periodistas a quienes se les realizó esta entrevista semiestructurada trabajan, en la actualidad, en distintos medios de comunicación de la ciudad de Rosario, desde medios gráficos de tirada masiva y programas televisivos de información general hasta radios o portales que funcionan como cooperativas de trabajo.

Los apartados que se ofrecen a continuación presentan, en primer lugar, una sucinta caracterización de la población estudiada (datos sociodemográficos, formación y situación laboral actual). En segundo lugar, las principales características de los escenarios laborales analizados bajo el prisma de las desigualdades de género. En tercer lugar, las miradas de las entrevistadas sobre las trasformaciones registradas en los modos de concebir y de ejercer el trabajo periodístico. Y, por último, el alcance y el rol que tienen las redes y las nuevas tecnologías en contextos de alta movilidad social y radicalidad política. 
Las comunicadoras entrevistadas tienen entre 25 y 35 años, trabajan en medios de comunicación (radio, diarios, televisión, y medios "alternativos» de alcance local) $\mathrm{y}$ son integrantes del colectivo Ni Una Menos (Rosario) que tiene una activa participación en las asambleas organizadoras del 8M local. En términos generales, la mayoría no tiene familiares a cargo, son solteras y han alcanzado titulaciones superiores en Periodismo y Comunicación Social.

Respecto a la situación laboral, la mayoría trabaja en más de un medio de comunicación para garantizar su subsistencia. Al preguntar por los aportes feministas en su formación académica, todas ellas refieren que no contaron con capacitaciones vinculadas a los estudios de género y que sus conocimientos sobre estos aportes se construyeron durante el ejercicio profesional, por una necesidad «político-personal» más que por una exigencia de capacitación laboral.

\section{Caracterización de los entornos laborales}

Tal como hemos desarrollado en publicaciones anteriores, el ejercicio profesional dentro de las organizaciones periodísticas locales se estructura mediante mecanismos explícitos o invisibles que reproducen formas que desigualan la distribución de tareas, de cargos y de roles entre mujeres y varones (Rovetto, 2013; Rovetto \& Figueroa, 2015; Rovetto, 2017). Este fenómeno se da tanto en los medios de comunicación tradicionales y hegemónicos (prensa escrita, informativos televisivos, radios), como en los nuevos medios alternativos. Al respecto, las entrevistadas que distribuyen sus jornadas laborales en distintos medios afirman estar en "alerta permanente» para revertir situaciones de desigualdad en el reparto de tareas y de toma de decisión dentro de las redacciones.

Asimismo, en la mayoría de los relatos las entrevistadas afirmaron haber atravesado a lo largo de sus carreras profesionales situaciones en las que se sintieran acosadas por sus compañeros o sus jefes. Los relatos incluyen hechos que van desde abuso de poder, hasta situaciones de maltrato cotidiano y de discriminación, agravada por referenciarse como «feministas» en el ejercicio de su profesión. 
En estos contextos laborales adversos, las entrevistadas reconocen sus esfuerzos rutinarios por desarrollar temas y por producir contenido desde una perspectiva de género, lo que consideran pequeños aportes al movimiento de mujeres. Ciertamente, dan cuenta de estas prácticas informativas en términos protectivos: «Hay notas que tenemos que defender». Aunque necesaria, resulta paradójica la tarea defensiva que las ubica, una vez más, en el orden de los cuidados, para referirse nada más ni nada menos que al producto de su trabajo:

Con las notas de género, sí me pasó tener que defender la nota (...) yo era muy mala para defenderme, entonces me largaba a llorar enseguida, no podía defender nada y me iba al baño. Salía toda colorada, y decía, bueno está bien, no hago nada, y me iba. Era una discusión constante con el jefe y a veces también con toda la sección (H., comunicación personal, 2018).

Hay que defender mucho la publicación de noticias vinculadas a las problemáticas de género que no tengan que ver con la violencia (M., comunicación personal, 2018).

En sus prácticas cotidianas, interpelan las rutinas de trabajo periodísticas, apelando a la incorporación de un lenguaje no sexista y procurando la pluralidad de voces en las fuentes, entre otros desafíos:

Mi propósito, ahora, atraviesa toda la agenda. Hacer un periodismo feminista o con perspectiva de género que no sea cubrir mujeres que hacen cosas, sino una perspectiva distinta en cualquier problemática o temática que hagamos. Desde el bache, la vivienda hasta la economía. Porque en algún punto no sé si es lo que me gusta hacer, pero sí siento que es como tiene que ser (D., comunicación personal, 2018).

Es que, a lo largo de estos años, su trabajo periodístico fue enriqueciéndose de una perspectiva feminista que cuestiona de manera integral los mecanismos con que se reproducen las desigualdades de género en la producción de contenido informativo. 
En relación con el modo en que el feminismo irrumpió en sus historias de vida y con las repercusiones que trajo aparejada su referencia con las luchas actuales del movimiento, todas las entrevistadas señalan que si bien este acercamiento les posibilitó grandes avances en formas de concientización sobre sus experiencias personales y profesionales, también implicó redoblar los esfuerzos para desarrollarse en sus espacios de trabajo:

Ser feminista es más trabajoso que no serlo, es más difícil, y es muy cansador. Sobre todo, cuando tenés que explicar todo y decís: «Loco, hace un esfuerzo vos...». Pero, además de eso, creo que te reafirma en un montón de cosas, te quita un montón de inseguridades, te podés aceptar más (...) no sé cómo explicarlo, te sentís más poderosa, te quita miedos, es un camino de ida... (D., comunicación personal, 2018).

Ser feminista en una redacción periodística hoy implica más trabajo y estar siempre en alerta, porque siempre te cuestionan (F., comunicación personal, 2018).

$\mathrm{Al}$ conversar sobre la dinámica con la que se establece el vínculo entre feminismos y medios de comunicación en la agenda, señalan:

Celebro mucho que en la televisión se haya invitado a comunicadoras feministas como Pichot y Mengolini, ${ }^{10}$ por la masividad y el nivel de penetración de los programas televisivos y porque se está revirtiendo lo que siempre decíamos: «A la tele le falta feministas» (F., comunicación personal, 2018).

Hemos aprovechado la ola y lo resolvimos con altura. Teníamos que llegar al público que mira los programas de chimentos y lo hicimos. Teníamos que hablarles a las amas de casa, a las adolescentes, a las abuelas, derribar prejuicios y mitos en torno al feminismo. Si pretendemos transformaciones radicales y en la vida real, tenemos que estar en el programa Intrusos (H., comunicación personal, 2018). 
Ahí teníamos que llegar tarde o temprano, aunque en parte sea porque ahora «vende» (D., comunicación personal, 2018).

La irrupción impertinente del feminismo en los canales de televisión de alcance nacional, producidos en la capital del país, no tuvo su correlato en los medios locales de la ciudad de Rosario, lastrados por esquemas tradicionales y androcéntricos, y con varones como productores y como jefes de redacción:

Mi jefe no tiene idea de nada. Viene un día y me dice: «¿Sabés lo que estuvo hoy todo el día en pantalla, que hay que poner... jel feminismo!». Lo siguiente que me dice es: «Existe en Rosario alguien que pueda hablar del tema? Porque está bueno traer el tema con una perspectiva local» (H., comunicación personal, 2018).

Es que en Rosario las empresas mediáticas no logran dilucidar lo revulsivo que puede llegar a ser la puesta en circulación del discurso feminista.

De lo que me di cuenta, es que no hay una bajada de línea política directa contra el feminismo (...) porque, en realidad, no les interesa. No es un tema que les implique algún costo en términos publicitarios, al menos no de forma directa. Por eso creo que las feministas en las redacciones nos tenemos que aprovechar de esa situación y hacer noticias con perspectiva de género y mucha profundidad. Por ahora no se dan cuenta de lo que eso implica (risas) (D., comunicación personal, 2018).

Las redes sociales en la ampliación de horizontes profesionales y políticos

Respecto del alcance que tienen las redes sociales y las nuevas herramientas de comunicación para el desarrollo de sus carreras profesionales y de sus prácticas militantes, las entrevistadas plantearon puntos de vista discordantes. Por un lado, señalaron: «Muchas veces nos leemos entre nosotras, es decir, el contenido que producimos, sobre todo en los medios no hegemónicos, se transmite en un circuito cerrado». Por otro, pusieron en duda la potencialidad «real» de las redes sociales 
para alcanzar las transformaciones necesarias que los feminismos están proponiendo en todo el mundo. Aunque todas las entrevistadas coinciden en que, en la actualidad, resultan imprescindibles para estar conectadas globalmente y para las estrategias políticas que pretenden avanzar con mayores niveles de popularidad y de adhesión.

$\mathrm{Al}$ respecto, sostienen que en los últimos años el crecimiento del movimiento de mujeres y feminista se debe a haber tomado tanto «las calles como las redes» para contagiar en términos más pedagógicos sus demandas y sus reivindicaciones.

Sin dudas el movimiento de mujeres creció en visibilidad y en masividad gracias la circulación de sus propuestas en las plataformas sociales. Esto ha favorecido mucho más a su amplificación que tal o cual organización política. ¡Y está buenísimo! porque muchas sostenemos una militancia que siempre fue más under, desde abajo (F., comunicación personal, 2018).

Con las redes sociales creo que se generan microcircuitos donde una piensa que hay un montón de gente de acuerdo con un montón de cosas que publicás. Pero, en general, son todos sus amigos (risas) (D., comunicación personal, 2018).

Las redes sociales tienen un rol primordial, son un espacio de discusión y de información, de alguna forma nos estamos encontrando todas en Twitter, con algún hashtag, como el \#MeToo, y así también empezamos a contar experiencias de abusos que nos hermanaban a casi todas y que de otra manera no hubieran emergido con tanta potencia. Las TIC nos conectan y es una forma de estar juntas. $\mathrm{Y}$ eso tiene mucha repercusión individuales y colectivas (S., comunicación personal, 2018).

Por último, al conversar sobre las fuentes informativas feministas consultadas para la elaboración de contenidos noticiosos, las entrevistadas, en su mayoría, señalan que, en la actualidad, hay portales o agencias feministas insoslayables que utilizan cotidianamente como herramientas de trabajo. 


\section{Consideraciones finales}

Este apartado no tiene pretensiones conclusivas ni procura responder acabadamente las preguntas que originaron esta nueva aproximación al campo de las relaciones de género en los escenarios de producción periodística actuales. Somos conscientes que otras dimensiones relacionadas con las condiciones de trabajo y con los crecientes niveles de precarización y de flexibilización laboral en el sector son aspectos cruciales para comprender integralmente el fenómeno estudiado. También entendemos que estas dimensiones están atravesadas por problemas estructurales y por dificultades cotidianas que tienen su origen en la naturaleza jerárquica de las relaciones laborales dentro del lugar de trabajo, como en la falta de poder que tienen las trabajadoras en general.

Las demandas y las reivindicaciones históricas impulsadas por las mujeres en el sector son recurrentes porque se topan, sistemáticamente, con la impermeabilidad de las empresas de comunicación, sus administradores y otros varones periodistas que ocupan lugares privilegiados de tomas de decisión en las redacciones. Así, la desoída necesidad de incorporar la perspectiva de género en las redacciones, la ausencia de medidas que favorezcan la «real» igualdad de oportunidades entre varones y mujeres, como la existencia de condiciones que perpetúan la violencia machista, la violencia sexual y su impunidad, son los factores más cuestionados por las nuevas generaciones de mujeres que se incorporan a la profesión periodística.

Con este trabajo hemos procurado iluminar las acciones colectivas de un grupo de profesionales a las que denominamos perio-feministas, sus modos de agenciamiento y de resistencia al interior de los medios informativos, así como sus vínculos y sus estrategias de articulación con el movimiento de mujeres más amplio en un contexto en el que sus prácticas profesionales son fundamentales para visibilizar las demandas sociales.

Sin dudas, dentro de los repertorios de acción política que vienen pujando por construir ese «nuevo orden civilizatorio» del que nos habla María Luisa Femenías (2002) están los elaborados por los feminismos a nivel global, que interpelan estructuras establecidas con el fin de transformarlas. En este marco, las organizaciones y las colectivas feministas como NUM, avanzan cuestionando la división sexual del trabajo presente en los medios de comunicación, con algunas certezas, no pocas dificultades y grandes esperanzas. 
Los seis encuentros que mantuvimos con las jóvenes periodistas entrevistadas nos permitieron reflexionar sobre el desarrollo de sus carreras profesionales y sobre su participación en la dinámica actual del movimiento de mujeres, y pusieron de manifiesto las tensiones entre trabajo periodístico y militancia feminista con las que conviven a diario.

Las narrativas construidas con las jóvenes periodistas en los sucesivos encuentros, aportan claves interpretativas para comprender el calado de las desigualdades de género en los medios de comunicación locales, así como las estrategias de resistencia elaboradas colectivamente para enfrentarlas. En este sentido, se percibe que dentro de las cuestiones que operan en la selección de jefes varones para ocupar determinados espacios ocupa un lugar preponderante la vinculación de los medios como empresas con otros intereses y capitales en juego.

En la actualidad, la función de los medios de comunicación como espacios de democratización de la información está bastante vapuleada, y ha puesto en crisis las cuestiones referidas a la ética periodística y a los valores que implica comunicar con responsabilidad. Según la percepción de las entrevistadas, en mayor medida, son los varones periodistas quienes suelen estar más disponibles a la hora de dejar primar intereses económicos personales y de anteponerlos a los valores éticos del compromiso con la verdad. Las mujeres periodistas, por el contrario, demuestran en estos espacios una tendencia a establecer un vínculo de nobleza con su profesión desde un lugar de compromiso al informar.

En este contexto, el rol de las periodistas con perspectiva de género, o periofeministas, como preferimos definirlas en nuestro estudio, nos invita a observar dos aspectos que consideramos estrechamente relacionados: la centralidad de las nuevas tecnologías y de las redes sociales en este proceso, y las estrategias desplegadas por muchas periodistas y comunicadoras en articulación con las organizaciones del movimiento de mujeres más amplio (Boix \& de Miguel, 2013; Laudano, 2015, 2016).

Esta convergencia virtuosa, contribuye a aumentar las posibilidades de producción y de circulación de sentidos que, hasta el presente, eran vistos como marginales y como excluidos de las lógicas hegemónicas propias de los discursos dominantes de circulación masiva. 
En la actualidad, las perio-feministas establecen redes y alianzas internacionales. Sus prácticas informativas se reconocen en los clásicos formatos de agencias de noticias, listas de distribución, revistas y periódicos; en los medios comunitarios y autogestivos que ofrecen innovadores servicios comunicacionales; o abriéndose paso desde los márgenes en las grietas de los medios convencionales, convirtiéndose en segmentos específicos (suplementos y columnas) que luego son replicados en las redes sociales.

Asimismo, esta exploración nos acercó al conjunto de estrategias de supervivencia y de acción política que las jóvenes periodistas ponen en juego tanto dentro como fuera de los escenarios de producción, y que hace emerger una pregunta que se abre indefectiblemente hacia el futuro: ¿qué implica hacer periodismo hoy?

El trabajo realizado cotidianamente en medios, y su participación activa en el movimiento de mujeres y de defensa de los derechos, va de la mano de la articulación y de la conformación de espacios de encuentro, de contención y de organización entre las mujeres con quienes comparten espacios de trabajo. Tejer redes de intercambio y establecer vínculos desde la sororidad con colegas mujeres que atraviesan situaciones similares es parte de las estrategias de supervivencia cotidianas de estas perio-feministas.

\section{Referencias}

Arfuch, L. (2008). Crítica cultural entre política y poética.

Buenos Aires, Argentina: Fondo de Cultura Económica.

Boix, M. y de Miguel, A. (2013). «Los géneros de la red:

los ciberfeminismos». En G. Natansohn (Coord.), Internet en código

femenino (pp. 37-73). Buenos Aires, Argentina: La Crujía.

Díaz, P. (11 de julio de 2017) El resurgir del feminismo: ¿estamos

ante la cuarta ola? MAS. Mujeres a seguir. Recuperado de

http://www.mujeresaseguir.com/social/noticia/1107921048615/resurgi

r-del-feminismo-cuarta-ola.1.html 
Femenías, M. L. (comp.) (2002). Perfiles del feminismo

iberoamericano. Buenos Aires, Argentina: Catálogos.

Entrevista a Nancy Fraser: el feminismo del 99\% y la era Trump (13 de mayo de 2017). ContrahegemoníaWeb. Recuperado de http://contrahegemoniaweb.com.ar/entrevista-a-nancy-fraser-elfeminismo-del-99-y-la-era-trump/

Las periodistas paramos (s/f). Más de 8.000 mujeres firman nuestro manifiesto para el 8M. Recuperado de https://lasperiodistasparamos.wordpress.com/

Laudano, C. (3 de agosto de 2015). Movilización por NiUnaMenos: entre el activismo digital y \#ElFeminismoLoHizo. Marcha. Recuperado de http://www.marcha.org.ar/movilizacion-porniunamenos-entre-el-activismo-digital-y-elfeminismolohizo

Laudano, C. (2016). «Feministas en "la red". Reflexiones en torno a las potencialidades y restricciones de la participación en el ciberespacio». En F. Rovetto y L. Fabbri (Eds.), Sin feminismos no hay democracia (pp. 31-54). Rosario, Argentina: Último recurso.

Löcher, J. (2 de marzo de 2018). Feministas en todas partes. Una lectura de la explosión mediática alrededor del feminismo por Claudia Laudano. Del mar al caracol. Recuperado de http://revistadelmaralcaracol.com.ar/mar-de-medios/feministas-todaspartes-una-lectura-la-explosion-mediatica-alrededor-del-feminismoclaudia-laudano/

López, M. P. (2 de junio de 2015). Ni una menos: aquelarre y algarabía. Página/12. Recuperado de http://www.pagina12.com.ar/diario/sociedad/3-273992-2015-0602.html

Palomo, A. (3 de abril de 2018). María Moreno: memorias de periodismo y licor. Pikara Magazine. Recuperado de http://www.pikaramagazine.com/2018/04/maria-moreno/ 
Richard, N. (2009). La crítica feminista como modelo de crítica cultural. Revista Debate feminista, 20(40), 75-85.

Rovetto, F. (2013). Percepciones sobre desigualdades de género en el trabajo periodístico. Global Media Journal, 10(20), 54-73.

Recuperado de https://journals.tdl.org/gmjei/index.php/GMJ_EI/article/view/164

Rovetto, F. (2015) Violencia contra las mujeres: comunicación visual y acción política en «Ni una Menos» y «Vivas nos Queremos».

Contratexto, (24), 13-34. doi:

http://dx.doi.org/10.26439/contratexto2015.n024.585

Rovetto, F. y Figueroa, L. (2015). La cocina del trabajo periodístico. Desigualdades de género y producción informativa, el caso de la provincia de Santa Fe. Question, (48), 494-509. Recuperado de https://perio.unlp.edu.ar/ojs/index.php/question/article/view/2711

Rovetto, F. (2017). Igualdad de oportunidades y trabajo periodístico. Retos, retóricas y obstáculos. Revista Internacional de Comunicación y Desarrollo, 2(6), 35-45. doi: http://dx.doi.org/10.15304/ricd.2.6.3976

Rosales, M. B. (2016). \#NiUnaMenos y los debates fundantes en comunicación y género. Con $X,(2)$. Recuperado de https://perio.unlp.edu.ar/ojs/index.php/conequis/article/view/CXe10

Spataro, C. (2018). Abajo el feministómetro. Bordes. Revista de Política, Derecho y Sociedad, VIII. Recuperado de http://revistabordes.com.ar/abajo-el-feministometro/

Toret, J. (2013). Tecnopolítica: la potencia de las multitudes conectadas. El sistema red. 15M, un nuevo paradigma de la política distribuida. IN3 Working Paper Series. Barcelona, España: UOC. Recuperado de http://tecnopolitica.net/sites/default/files/toret.pdf

Schmidt, S. (16 de octubre de 2017). \#MeToo: Harvey Weinstein case moves thousands to tell their own stories of abuse, break silence.

The Washington Post. Recuperado de 
https://www.washingtonpost.com/news/morning-

mix/wp/2017/10/16/me-too-alyssa-milano-urged-assault-victims-to-

tweet-in-solidarity-the-response-was-

massive/?noredirect=on\&utm_term $=.33 \mathrm{a} 77 \mathrm{~b} 0 \mathrm{e} 3 \mathrm{f} 53$

Verón, E. (1987). La semiosis social. Fragmentos de una teoría

de la discursividad. Buenos Aires, Argentina: Gedisa.

Zafra, R. (2014). Arte, feminismo y tecnología. Reflexiones sobre

formas creativas y formas de domesticación. Quaderns de Psicología, 16(1), 97-109.

\section{Notas}

1 Sobre esta irrupción mediática y su expansión viral, consultar la entrevista a Claudia Laudano (Löcher, 2018).

2 Respecto al colectivo NUM, que por su impacto social y sus configuraciones particulares en distintas ciudades del país merecería una caracterización más detallada, diremos que, en el marco de su etapa de emergencia pública, en la convocatoria a la movilización del 3 de junio de 2015 con la consigna \#BastaDeFemicidios se organizó a partir de la conformación de un grupo de periodistas y de comunicadoras reconocidas por su trabajo en medios.

3 Según Claudia Laudano (2015), el 17 de mayo de 2015 la cuenta oficial de Twitter@NiUnaMenos tenía 8 mil seguidores y produjo unos 760 tuits desde su apertura. Durante los días de la convocatoria, se generaron 958 mil menciones con el hashtag \#NiUnaMenos, que alcanzó posición de trending topic nacional y mundial. En Facebook, a principios de junio, la cuenta de NUM registraba más de 130 mil me gusta.

4 El Paro Internacional de Mujeres o Huelga Internacional Feminista (8M) se organizó por segundo año consecutivo el 8 de marzo de 2018, Día Internacional de la Mujer Trabajadora. En esta oportunidad, fue convocado por organizaciones feministas y aliadas de la lucha por los derechos de las mujeres en todo el mundo y contó con la adhesión de más de 170 países y una gran cantidad de actividades internacionales y localmente organizadas.

5 La tendencia \#MeToo en EE.UU., iniciada de forma viral como hashtag en las redes sociales en octubre de 2017 para denunciar la agresión sexual y el acoso sexual, fue popularizada por la actriz Alyssa Milano, quien animó a las mujeres a tuitear sus experiencias para demostrar la naturaleza extendida del comportamiento misógino. Desde 
entonces, el hashtag ha sido utilizado por más de 500.000 personas, entre ellas muchas celebridades (Schmidt, 2017).

$6 \mathrm{El}$ periodismo con enfoque de género es llevado adelante, mayoritariamente, por mujeres nucleadas en asociaciones y en redes que circulan por carriles paralelos a los medios informativos tradicionales, creando agencias de noticias con proyección internacional, valiéndose de los recursos y los alcances que proveen las nuevas tecnologías, pero con escasa incidencia masiva en los territorios nacionales. Como ejemplos regionales de estos espacios de comunicación iberoamericanos podemos mencionar la Red Internacional de Periodistas con Visión de Género (RIPVG), fundada en 2005, y a Periodistas de Argentina en Red/Por una comunicación no sexista (PAR), fundada en 2006.

7 La entrevista fue realizada en Nueva York en los días previos al 8 de marzo. La versión original en video (en inglés) puede consultarse en https://www.youtube.com/watch?v=BlLwkPcmYuI

8 Actualmente, las periodistas se reúnen periódicamente para evaluar estrategias de acción y siguen sumando adhesiones al Manifiesto.

9 Nos referimos al proyecto de investigación «Género, cultura periodística y precarización laboral en los procesos productivos de los medios de comunicación de la provincia de Santa Fe», dirigido por la Dra. Florencia Rovetto y realizado en el marco del Consejo Nacional de Investigaciones Científicas y Técnicas (CONICET) durante el bienio 2016-2017.

10 Malena Pichot y Julia Mengolini son dos de las figuras mediáticas que se más se referenciaron a partir de este fenómeno de popularización del feminismo en la Argentina. 